\title{
HYPERSENSITIVE RESPONSE: “A PLAYER IN PLANT DEFENSE”
}

\author{
ARPITA MISHRA \& NEHA TIWARI \\ IILM-College of Engineering and Technology, Greater Noida, India
}

\begin{abstract}
Plants have developed sophisticated mechanisms to protect themselves from various diseases. Besides preformed physical and chemical barrier that hinders infection, a wide range of defence responses are induced only after pathogen attack. These responses include translocation of $\mathrm{Ca}^{2+}$ and protons across the plasma membrane into the cytosol, hypersensitive response, protein phosphorylation/ dephosphorylation, activation of enzymes that generate ROS such as NADPH-oxidase and peroxidase, accumulation of NO and SA and expression of defense related genes. Hypersensitive response is one of the immediate defence mechanisms of plant against pathogen infection. It is a form of programmed cell death (PCD) that helps in restricting the pathogen growth. Present review includes the role of hypersensitive response in defense, molecular marker of hypersensitive response and the components of major signalling pathways that play an important role in defence. This review will give us an insight on hypersensitive response (HR) of plants with respect to the physiological, biochemical and molecular determinants in different plant species.

KEYWORDS: Hypersensitive Respo nse, Map Kinase, SAR, Plant Defence and HSR203J
\end{abstract}

Received: May 29, 2017; Accepted: Jun 20, 2017; Published: Jun 29, 2017; Paper Id.: IJBTRAUG20171

\section{INTRODUCTIONS}

Plants are a source of food and shelter by a wide range of microorganisms including viruses, bacteria, nematodes and insects. Many of these microbes act as pathogens that impair plant growth and development. However, plants have developed diverse strategies to defend themselves. They respond to infection using twobranched innate immune system. The first branch uses trans-membrane pattern recognition receptors (PRR) that responds to slowly evolving microbial or pathogen-associated molecular pattern (PAMP) such as flagellin or chitin, a component of fungal cell walls (Jones and Dangl, 2006). During interaction with virulent parasites, PRRs confer weak immune responses that attenuates pathogen growth and contribute to basal defence. Reduced PAMPmediated defence probably results from successful host defence suppression by pathogen effectors. The second branch acts largely through protein products encoded by most Resistance genes ( $R$ genes) (Jones and Dangl, 2006). Resistance $(R)$ proteins represents mainly intracellular, immune receptor class having the capacity to directly or indirectly detect isolate-specific pathogen effectors, encoded by avirulence (avr) genes. Recognition requires the presence of matching $a v r$ and $R$ genes in the two species and is thought to be mediated by ligand receptor binding (Glazebrook, 1999). Efforts have been made to elucidate plant-pathogen interaction leading to the identification and cloning of several $a v r$ and $R$ genes (Keen and Staskawicz, 1998; Dangl, 1995). In conclusion, the multi-component response of plants to pathogens in host and non-host resistance appears to be activated by ligand receptor interactions, in which avr gene products and PAMPs serve as ligands for plasma membrane located or cytosolic receptors (Odjakova and Hadjiivanova, 2001).

Receptor mediated recognition initiates cellular and systemic signaling processes that activate 
multicomponent defense responses at local and systemic levels resulting in rapid establishment of local resistance and delayed development of systemic acquired resistance (Scheel, 1998). The earliest reactions of plant cells include change in plasma membrane permeability leading to $\mathrm{Ca}^{2+}$ and proton influx and $\mathrm{K}^{+}$and $\mathrm{Cl}^{-}$efflux (Mc Dowell and Dangl, 2000). Ion fluxes subsequently induce production of reactive oxygen species (ROS), such as superoxide $\left(\mathrm{O}_{2}^{-}\right)$, hydrogen peroxide $\left(\mathrm{H}_{2} \mathrm{O}_{2}\right)$ and hydroxyl free radical $\left(\mathrm{OH}^{\circ}\right)$. Localized production of ROS and nitric oxide (NO) acts as second messenger for HR induction and defense gene expression (Piffanelli et al., 1999). In systemic defense, signal is mediated by several molecules which function as messengers in plants, for example, salicylic acid (SA) and jasmonic acid (JA), or even volatiles such as NO and ethylene (ET) (Baker $\boldsymbol{e t}$ al., 1997). These messengers interact with specific binding proteins that are implicated in the transcriptional activation of pathogenesis related genes in response to pathogen aggression including hypersensitive response (Montesinos et al., 2002).

This review aims to summarize some of the recent findings on hypersensitive response, the physiological, biochemical and molecular machineries of the HR. Role of elicitors, reactive oxygen species is also discussed. Present review also includes MAP kinase, a component of the signalling pathway. As HR is a form of programmed cell death (PCD) associated with plant response to pathogens, a description of main morphological and biochemical determinants of PCD is also discussed.

\section{Hypersensitive Response (HR)}

Among the vast array of defense strategies to combat the disease, the most efficient and immediate resistance reaction against pathogen attack is the hypersensitive response. HR is defined as "the rapid death of plant cells in association with restriction of pathogen growth" (Good man and Novacky, 1994). It is recognized by the presence of brown, dead cells at the site of infection. Klement $(1971 ; 1986)$ defined three phases in the HR to plant pathogenic bacteria:

- INDUCTION PHASE, requiring the presence of living bacteria in the intercellular spaces. Avirulence (avr) genes are activated in bacteria and the avr gene products are delivered directly into the host cells by a special secretory mechanism.

- LATENT PHASE, during which living bacteria is no longer required. No macroscopic symptoms occur during this phase, but changes in the physiology of the plant cells can be detected. During this phase the irreversible membrane damage associated with the HR occurs.

- PRESENTATION or COLLAPSE PHASE, during which host cells in the inoculated region collapse and desiccate.

However, the duration of these three phases depends upon the host pathogen combination and the environmental conditions.

HR accompanies "incompatible interaction" and has been thought to play important role in disease resistance. Recent studies have shown that hypersensitive response is an active process and is a form of programmed cell death (Greenberg, 1997). The hypersensitive response occurs as a result of initial identification events between host and pathogen, which are mediated by the plant resistance $(\mathrm{R})$ and microbial avirulence (avr) genes (Flor, 1971). In case of 
biotrophs, HR mediated cell death alone is sufficient to restrict the pathogen infection. In an interaction with obligate biotrophic pathogens that form historical associations with host cells, plant cell death would deprive the pathogen of access to further nutrients. However, the role of HR is less clear in necrotrophs (Hammond-Kosack and Jones, 1996). The HR may cause pathogen arrest, but may also occur as a consequence of the activation of other defense response. Most of the $\mathrm{R}$ gene-dependent resistance is associated with $\mathrm{HR}$ where $\mathrm{R}$ proteins emit signals that feed into cell death pathways. However, in some cases HR-independent resistance has been observed. In tomato, Cf- 9 codes for a membrane-anchored $R$ gene providing resistance against cladosporium fulvum (Jones et al., 1994). The amount of $\mathrm{R}$ and avr protein or the duration of $a v r$ expression, determines whether resistance occurs with or without HR (Shirasu and Schulze-lefert, 2000).

HR, is highly complex defence response, along with the production of reactive oxygen species (Lamb and Dixon, 1997), modification of ion fluxes (Levine et al., 1996), is followed by activation of defence signal through the synthesis of signaling molecules such as jasmonic acid, salicylic acid and protein kinases (Dangl et al., 1996; Dixon et al., 1994). Salicylic acid collection leads to the onset of systemic acquired resistance in distal plant tissue (Ryals et al., 1996). These events are accompanied by the activation of several plant defense genes, local accumulation of pathogenesis related (PR) proteins, activation of transcription factors and degradation of proteins by the polyubiquitin system and cell death. These events limit the nutrient availability to the pathogens thereby restricting the spread of the pathogen (Dixon and Harrison, 1990).

\section{MOLECULAR MARKER OF HYPERSENSITIVE RESPONSE}

Although the molecular mechanism leading to the establishment of HR and active components of cell suicide still remains obscure, recent insight has been obtained in identification of useful genes which are activated during HR and are better known as marker gene of HR.

The tobacco hsr203J gene has been shown to be a molecular marker of the hypersensitive response (Pontier $\boldsymbol{e t}$ al., 1994). The hsr203J gene is activated during the early steps of incompatible plant/pathogen interaction between tobacco and $R$. solanacearum. The analysis of the recombinant protein demonstrated that the $h s r 203 J$ gene product is a serine hydrolase having esterase activity (Baudouin $\boldsymbol{e t}$ al., 1997). The functional characterization of the gene product as an esterase, suggest either a role in the control of cell death, or a function in the establishment or limitation of cell death. The effect of other hypersensitive response (HR)-inducing pathogens and elicitors has been tested with transgenic plants containing the $h s r 203 J$ promoter-GUS reporter fusion gene and the preferential inducibility of the $h s r 203 J$ gene promoter during incompatible interaction was found (Pontier et al., 1994). Homologues of hsr203J has been found in tomato and the expression of Cladosporium fulvum avirulence avr 9 gene product in the tomato line containing the $C f$ - 9 defense resistance gene led to rapid $h s r 203 J$ gene activation. The relationship between the activation of $h s r 203 J$ and cell death has been envisaged and expression of hsr203J gene has been found to be tightly correlated with programmed cell death (Pontier et al., 1998). Among potential effectors of HR such as SA, MeJ and INA, most of them were found to have effect on $h s r$ gene expression in tomato (Pontier et al., 1998). The hsr203J gene is not activated during plant development and does not respond to classical elicitors such as fungal cell walls and its expression is dependent on the integrity of bacterial hypersensitive response and pathogenecity ( $h r p$ ) genes (Pontier et al., 1994). The P. solanacearum isolate and harpin, a protein from Erwinia amylovora secreted via hrp genes are able to elicit an hypersensitive reaction in plants and are inducer of $h s r$ gene (Wie et al., 1992; Boucher et al., 1992). Harpin was shown to trigger the expression of the hsr203JGUS fusion in tobacco (Pontier et al., 1994). Histochemical GUS detection of tobacco leaves locally infiltrated with 
Pseudomonas fluorescens with or without the hrp Z gene of $P$. syringae pv. syringae revealed the highly localized nature of the hsr203J in response to harpin (Pontier et al., 1998). Similarly, in case of $R$. solanacearum, the hsr203J promoter induction was strictly confined to the inoculated site and depended on the presence of functional hrp genes. During an incompatible interaction between tobacco and the bacterial phytopathogen Pseudomonas solanacearum, hsr201 and $h s r 215$ genes were expressed preferentially during hypersensitive reaction. The induction of these genes was confined to infected areas confirming its localised nature. Though HR is considered to be important element of plant disease resistance but with a necrotrophic pathogen like Botrytis cineria, the HR facilitates its colonization in the plant (Govrin and Levine, 2000). Although the $H R$ is a common feature of many resistance reactions, it is not an obligatory component. Some resistance reactions, such as those mediated by the mlo gene of barley towards the fungus Erysiphe graminis f. sp. Hordei, precede the induction of a visible HR (Shira Su and Schulze-Lefert, 2000). The molecular mechanism behind the HR still remains unclear, although a few loci such as eds-1, ndr-1or rar-1 (Century et al., 1995; Parker et al., 1996; Peterhansel et al., 1997) involved in signaling pathways leading to HR have been identified. eds- 1 is a key component of disease resistance pathways activated by the TIR-NBS-LRR class of resistance genes in response to bacterial and oomycete pathogens. Antisense tobacco plants with reduced ascorbate peroxidise and catalase responsible for detoxifying ROS were found to be hyper responsive to pathogen attack (Mittler et al., 1999). Antisense suppression of hsr203J in tobacco was found to accelerate the development of hypersensitive response in response to avirulent pathogens and a restriction of pathogen growth. Also a strong reduction of defense gene expression in cells undergoing HR was found (Tronchet et al., 2001). hsr203J, identified and cloned in Brassica juncea is analyzed for its expression at different stages of infection in susceptible and tolerant genotypes and has been found to be associated with defence (Mishra A et al.,2010).

Lesion-mimic mutants of Arabidopsis suggest the existence of genes involved in HR regulation (Lorrain et al., 2003). LSD 1 expressed constitutively in plants coding for zinc finger protein is suggested to act as negative regulator of HR (Dietrich et al., 1997). Nt LRP1 (N.tabacum Leucine Rich Protein 1) a tobacco gene has been found to have possible role as a modulator of the HR (Jacques et al., 2006). Gain of function revealed that Nt LRP1 expression is induced early during the HR initiated by elicitins, Ralstonia solanacearum or Tobacco mosaic virus. Besides hsr203J there are few other marker genes for HR and Harpin-induced1 gene (Hinl) is one of them.

Besides hsr, several other genes, such as Eli 3 (Kiedrowski et al., 1992) and AIG1 (Reuber and Ausubel, 1996) from Arabidopsis thaliana, or hinl from tobacco (Gopalan et al., 1996), were also identified as pathogen-induced genes that are specifically activated by signaling molecules generated during an HR. Eli 3 activation was found to be dependent on RPM1 resistance locus. Hinl, isolated by substractive hybridisation method has been found to be induced in a bacterial hrp gene-dependent manner, and in response to bacterial strains containing the avr pto gene.

Differential hybridization approach was used to isolate HIN1 (Gopalan et al., 1996) and two closely Hinl-related genes as downstream target in the spermine-signaling pathway (Takahashi et al., 2004). Spermine (spm), a major polyamine in plant transduces defense response and is identified as endogenous inducer of pathogenesis related-protein during TMV-induced HR. Pharmacological and biochemical analysis reveal that these marker genes are positioned downstream of spm-triggered mitochondrial malfunction (Takahashi et al., 2004). Other marker genes, hsr203J, HMGR, hsr201 and hsr515 were also found to be spm-responsive. Experiments have revealed that the induction of hinl, hsr203J and $H M G R$ genes by spm is independent of the SA-signaling pathway whereas expression of $h s r 201$ and $h s r 515$ was found to be partially dependent (Takahashi et al., 2004). 


\section{ROLE OF ELICITORS IN HR}

The aptness of some gram-negative bacterial pathogens, such as Pseudomonas, Xanthomonas and Erwinia strains, to cause disease in susceptible plants and elicit HR in resistant plants, is governed by the hrp (HR and pathogenecity) gene cluster (Bonas, 1994). hrp genes code for protein secretion pathway called type III secretion system (Van Gijsegem et al., 1993). It was found that mutation in hrp gene leads to the elimination of the bacterium ability to cause disease in susceptible plants and to trigger resistance in resistant plants (Huang et al., 1988). Harpins, a group of effector protein exported by the type III pathway of plants pathogenic Erwinia, Pseudomonas and Ralstonia spp. trigger HR (Galan and Collmer, 1999). Harpin has been reported to be expressed in tobacco only when it is produced in secretable form (Tampakaki and Panopovlos, 2000). Hypersensitive response-assisting protein (HRAP) is reported as an amphipathic plant protein isolated from sweet pepper that intensifies harpin pss (harpin derived from Pseudomonas Syringae pv syringae)-mediated hypersensitive response (Chen et al., 1998). The hrap gene is widely distributed in a broad range of plant species like tobacco, Arabidopsis and rice. The constitutive expression of hrap gene in transgenic tobacco plant enhances resistance against virulent bacterial pathogens by induction of a HR (Ger et al., 2002). Constitutive expression of the hrap gene in Arabidopsis results in an enhanced disease resistance towards E. carotovora subsp. carotovora. The disease resistance against virulent pathogen was found to be harpin dependent. Different biochemical and molecular markers like ion leakage, $\mathrm{H}_{2} \mathrm{O}_{2}$, protein kinase, Athsr3 and Athsr4 were found to be induced (Pandey et al., 2005). It was demonstrated previously that the harpin induced hypersensitive cell death is associated with altered mitochondrial function in tobacco cells (Xie and Chen, 2000).

\section{ROLE OF REACTIVE OXYGEN SPECIES IN HSR}

ROS are produced in plants through NADPH oxidases, amine oxidases and cell wall bound peroxidases and have been found to play role in biotic as well as abiotic stress. The generation of ROS in cell organelles like chloroplast and mitochondria are capable of inducing changes in the nuclear transcriptome, but the mechanism of signal transduction still remains unclear to some extent. In the chloroplast, plastoquinone (PQ), ascorbate, glutathione and ROS along with ferredoxin orthioredoxin system are the key signaling components (Pfannschmidt et al., 1999 and Choudhury et al., 2013 ). Peroxisomes are the major sites of $\mathrm{H} 2 \mathrm{O} 2$ production thorough different biochemical reactions. During photosynthesis in $\mathrm{C} 3$ plants, peroxisomes generate high amount of $\mathrm{H} 2 \mathrm{O} 2$ that is light dependent and as such the antioxidant efficiency is extensively high in those organelles (Foyer et al.,2003 and Choudhuryet al., 2013 ). These include enzymes like CAT, APX and those associated withascorbate/glutathione system (Foyer et al.,2003, Jimenez $\boldsymbol{e t}$ al.,1997 and Choudhury et al., 2013 ). Depending on the nature of the ROS, some are highly toxic and are rapidly detoxified. Detoxification of ROS is one of the defense mechanism in plants and may occur via enzymatic or non enzymatic pathways. The non-enzymatic defense system of the plant comprises of a variety of antioxidant moleculeorganic compounds such as amino acids (e.g Proline), quarternary and other amines (e.g. glycinebetaine and polyamines) and a variety of sugar and sugar alcohols (e.g. mannitol and trehalose), while the enzymatic one includes superoxide dismutase, ascorbate peroxidase, catalase, glutathione reductase and monohydroreductase. Antioxidant enzymes catalyze reactions that remove reactive oxygen species. Superoxide dismutase (SOD) converts $\mathrm{O}_{2}{ }^{--}$to $\mathrm{H}_{2} \mathrm{O}_{2}$ and then ascorbate peroxidise uses ascorbate as its specific electron donor to reduce $\mathrm{H}_{2} \mathrm{O}_{2}$ to water with concomitant generation of monodehydroascorbate (MDHA), a univalent oxidant radical of ascorbate2 MDHA spontaneously disproportionates into di-dehydroascorbate (DHA) and ascorbate. Based on the requirements of metal cofactor SODs are classified into three 
groups: Fe SOD, Mn SOD and Cu-Zn SOD. Fe SODs are located in the chloroplasts, Mn SODs are in mitochondria and peroxisomes and $\mathrm{Cu}-\mathrm{Zn}$ SODs in the chloroplasts, the cytosol and the extracellular (apoplast) space (Alscher et al,2002 and Kar, 2011). MDHA can also be directly reduced to ascorbate by the action of $\mathrm{NAD}(\mathrm{P}) \mathrm{H}-\mathrm{dependent}$ monodehydroascorbate reductase (MDHAR). Dehydroascorbate reductase (DHAR) uses reduced form of glutathione (GSH) to reduce DHA and thereby regenerate ascorbate. The oxidised glutathione (GSSG) is then converted to reduced glutathione by glutathione reductase (GR), by using $\mathrm{NAD}(\mathrm{P}) \mathrm{H}$ as the reducing power (Asada, 1992).

Whereas plants are glut with mechanisms to combat increased ROS level during abiotic stress conditions, in other circumstances plants appear to purposefully generate ROS as signaling molecule to control various process including pathogen defense and programmed cell death. The suppression of ROS detoxifying mechanism is crucial for the onset of PCD. Biotic stress results in the activation of NADPH oxidase and the repression of ascorbate peroxidase and catalase by salicylic acid and NO which leads to the overaccumulation of reactive oxygen intermediates (ROI) and activation of defense mechanism (Klessig et al., 2000). On the contrary, during abiotic stress, ROI-scavenging enzymes ascorbate peroxidase and catalase are induced to reduce the ROI level. Several roles for ROS during pathogen infections have been proposed: as direct antimicrobial agents, as activators of defense genes, as agents for cross linking proteins to limit pathogen infections (Bolwell et al., 1995) and as producers of HR, cell death, SA production and SAR (Lamb and Dixon, 1997).

The accumulation of reactive oxygen intermediates is a rapid event upon pathogen attack that precedes cell death in incompatible R gene triggered resistance reaction (Levine et al., 1994). The ROI have dose-dependent antagonistic action i.e. depending on the concentration of ROS three distinct phases characterize cellular responses to the oxidative stress (Levine et al., 1994). Low doses induce antioxidant enzymes like glutathione peroxidase; however, when the concentration of ROS reaches a certain threshold a signal transduction pathway that results in R-gene-dependent PCD, is activated (Levine et al., 1996). High doses results in necrosis. More molecular and genetic studies are referred to confirm the role of oxidative burst in the cell death.

\section{$\mathrm{H}_{2} \mathrm{O}_{2}$ AS A SIGNAL FOR HSR}

During oxidative burst $\mathrm{O}_{2}{ }^{-}$generated by a multi-subunit NADPH oxidase complex in the plasma membrane shows analogy to the oxidase in mammalian phagocytes and $\mathrm{O}_{2}{ }^{-}$is rapidly dismutated to $\mathrm{H}_{2} \mathrm{O}_{2}$ (Doke et al., 1996). In plants massive oxidative burst that generate high level of $\mathrm{H}_{2} \mathrm{O}_{2}$ have been observed in response to avirulent pathogen as part of the HR (Legendre et al., 1993; Lamb and Dixon, 1997). It was shown that enhanced $\mathrm{H}_{2} \mathrm{O}_{2}$ production during the HR led to dramatic increase in amount of cell death in a soybean cell culture system (Levine et al., 1994). However, when the role of ROS was investigated during the induction of TvX-triggered hypersensitive cell death it was suggested that production of ROS is not always necessary and the signal-transduction pathway leading to cell-death may exist independent of oxidative burst. Similar result was found during the $h s r 203 \mathrm{~J}$ gene activation in tomato and $\mathrm{H}_{2} \mathrm{O}_{2}$ and related metabolites were not found to play major role in the cell death, even at high concentration. It was suggested that a pathway not requiring ROS is involved or the ROS is insufficient as a cell death activator (Pontier et al., 1998). It was also observed that the signaling pathway might involve a serine protease (Yano et al., 1999). The role of $\mathrm{H}_{2} \mathrm{O}_{2}$ accumulation and hypersensitive cell death in barley against powdery mildew fungus was studied and a positive association between hypersensitive response mediated cell death and $\mathrm{H}_{2} \mathrm{O}_{2}$ production was observed. However, there was no accumulation of SA indicating that the salicylic acid is not provoked during cell death in barley (Huckelhoven et al., 1999). ROS have 
been shown to influence the expression of a number of important MAP kinases which phosphorylate a variety of substrates including transcription factors, other protein kinases, cytoskeleton-associated proteins and several stress associated genes, indicating a direct connection with the stress response, further complicated by the fact that ROS production can also be controlled by a MAP kinase cascade (Pitzschke and Hirt, 2006; Ren et al., 2002). The effect of $\mathrm{H}_{2} \mathrm{O}_{2}$ on $\mathrm{MAP}$ kinase activation was also investigated by kovtun et al. (2000) using Arabidopsis protoplast, and these workers found that it activated two MAP kinase of 42 and $44 \mathrm{kDa} . \mathrm{H}_{2} \mathrm{O}_{2}$ generation occurs both locally and systemically in response to wounding. Recent work shows that $\mathrm{H}_{2} \mathrm{O}_{2}$ functions as a second messenger mediating the systemic expression of various defense related genes in tomato plants (Orozco-Cardenas et al., 2001). Previously, it was found that the oxidative burst in pathogen challenged Arabidopsis leaves activates a secondary systemic burst in distal part of the plant, leading to systemic immunity via the expression of defense related genes (Alvarez et al., 1998).

\section{Role of MAP Kinases}

Extensive research has been done to elucidate the components of the pathway leading to the defense response. MAP kinase, member of serine/threonine protein kinase has been found to be an important component of signaltransduction pathway and is present in all eukaryotes. The cascade includes MAP kinase, MAP kinase kinase and MAP kinase kinase kinase. Active MAP kinase requires phosphorylation on tyrosine and threonine in the conserved threonine-Xtyrosine (TXY) sequence in kinase subdomain VIII (Peyne et al., 1991). A growing body of evidence suggest that MAP kinase cascades operate in plants. MAP kinases have been implicated in regulating certain aspects of plant growth and development, including cell division, hormone action and pollen development (Hirt, 2000; Tena et al., 2001; Zhang and Klessig, 2001). Various biotic and abiotic stresses also activate plant MAP kinase.

Mitogen-activated protein kinase (MAPK) signaling plays central roles in intracellular immunity pathways. Stimulus-triggered activation of a MAP kinase kinase kinase (MAP3K; also called MEKK) initiates MAP kinase signaling (Magnus et al., 2012). PRR directly or indirectly affect MAP3K activation, which in turn leads to the phosphorylation and thus the activation of downstream MAP kinase kinases (MAP2K; also called MKK or MEK) (Magnus et al., 2012). Molecular and biochemical analysis suggest that plant defense response involves MAP kinase activities (Romeis et al., 1999). Plant homolog for all three components of this cascade has been identified (Mizoguchi et al., 1998). Evidence that MAP kinase regulate innate immunity in plants has come from several studies. MAP kinase play role in signaling gene-forgene interaction-dependent defense response. It was found that tobacco cells, expressing the tomato $c f-9$ resistance gene, respond to avr 9 protein from the fungal pathogen Cladosporium fulvum by activation of MAP kinase (Romeis et al., 1999). Treatmnt of tobacco suspension cultured cells with a fungal elicitor, derived from the cells walls of Phytopthora infestans resulted in the transient activation of a 47KDa MAP kinase (Suzuki and Shinshi, 1995). MAP kinase 4 was hypothesized to function as a negative regulator of SAR. Evidence shows that MPK4 mutant in Arabidopsis exhibit constitutive SAR. Loss of MAP kinase 4 function leads to increased SA levels and exhibits enhanced resistance to virulent pathogens (Petersen et al., 2000). In addition to repressing SA-mediated defense, MPK4 is required for JA mediated gene expression. MAP kinase 4 may therefore, be involved in integrating SA and JA-dependent responses to selectively engage defenses against particular pathogen types or environmental stresses (Felton et al., 1999; Pieterse and van Loon, 1999). Similarly, a portion of MAP kinase cascade that positively regulates defense response was identified in N.tabacum (Yang et al., 2001). In tobacco two distinct member of MAP kinase is involved in the defense gene expression and HR like cell death against Tobacco mosaic virus. They are SA-induced protein kinase (SIPK) (Zhang and Klessig, 1997) and wound- 
induced protein kinase (WIPK) (Takahashi et al., 2003). SIPK is also activated by treatment of tobacco cells with different elicitors like parasiticein, cryptogein and a cell wall derived elicitor from the pathogenic fungus Phytophthora parasitica (Zhang et al., 1998). WIPK activation by TMV was found to depend on the disease-resistance $N$-gene and is an important component upstream of salicylic acid in the signal transduction pathways leading to local and systemic resistance to TMV (Zhang and Klessig, 1998). Nt Mek2, a MAP kinase upstream of both SIPK and WIPK was isolated (Yang et al., 2001) from tobacco. Expression of constitutively active Nt MEK2 (a MAP kinase kinase) led to the activation of SIPK and WIPK and, subsequently, induced HR-like cell death and defense gene expression. Gain of function and loss of function studies on MAP kinase cascade members reveal that the expression of spm-induced HR marker genes varies with respect to involvement of SIPK/WIPK activation. A complete Arabidopsis MAP kinase cascade, consisting of MEKK1, MKK4/MKK5 and MPK3/MPK6, that is activated in response to a 22-amino acid peptide derived from bacterial flagellin (flg22) was recently identified (Asai et al., 2002). Transient over-expression of constitutively activated MEKK1, MKK4 or MKK5 in Arabidopsis leaves enhanced resistance to bacterial and fungal pathogens, suggesting that this MAP kinase cascade plays an important role in signaling defense response. More than twenty MAP kinases have been cloned or genomically annotated in Arabidopsis, although their speicific functions remain unclear (Mizoguchi et al., 1997). These MAP kinases presumably act downstream of three major classes of putative MAP kinase kinase kinase typified by CTR1, ANPS and MEKK1. Yeast two-hybrid experiments show that MPK4, the MAP kinase kinase, AtMKK2, AtMEK1 and the MAP kinase kinase kinase, AtMEKK1 interact (Ichimura et al., 1998). The Arabidopsis homologues of WIPK and SIPK appear to be ATMPK3 and ATMPK6 respectively. Bacterial, fungal and plant derived defense response elicitors induced 45 and 49kDa MBP kinase activity in Arabidopsis suspension cultures cells and leaf tissues. Loss-of-function approach demonstrated that Arabidopsis MAP kinase 6 plays a role in resistance to certain pathogen. Silencing of MAP kinase 6 showed no apparent morphological phenotype or reduced fertility, indicating MPK6 is not required for development. Despite that, resistance to an avirulent strain of Peronospora parasitica and Pseudomonas syringae were compromised revealing its role in both resistance-gene mediated resistance as well as basal resistance (Menke et al., 2004).

It appears that plant MAP kinase pathway is not neatly delineated into separate parallel cascades. Some MAP kinases are known to be activated by common upstream elements, for example ATMPK3 and ATMPK6 by ANP1 through oxidative stress (Kovtun et al., 2000). However, although ATMPK4 and ATMPK6 share many similarities in their activation by stresses such as wounding (Ichimura et al., 2000). ANP1 will not activate ATMPK4 which is thought to be activating ATMEKK1 (Ichimura et al., 1998). Expression of MAP kinases during pathogenesis of Alternaria blight in mustard suggests that the signalling pathwqays might be differentially modulated by the pathogen to facilitate its colonization during different stages of infection( Mishra A et al.,2015). Hence, these MAP kinases could be attractive targets for genetic manipulation in order to develop resistant lines of Brassica (Mishra A et al.,2015).

\section{ROLE OF SALICYCLIC ACID IN HR}

Salicylic acid (SA), a phenolic compound(orthohydroxy benzoic acid) plays an important role in induction of plant defense against a variety of biotic and abiotic stresses through morphological, physiological and biochemical mechanisms(Abdul et al., 2011). SA synthesized by plants in response to a wide range of pathogens, and is essential for the establishment of local and systemic resistance (Loake and Grant, 2007; Vlot et al., 2009). The importance of SA arises 
from its role in the mediation of resistance $(R)$-gene resistance and basal immune responses, and from the positive link between SA-mediated defence and the small interfering RNA (siRNA) antiviral machinery (Alamillo et al., 2006; Baebler et al., 2014; Hunter et al., 2013).

The HR-mediated cell death is related to the induction SA known for pharmacological use were found to affect cell growth, differentiation and inflammation (Pillinger $\boldsymbol{e t}$ al., 1998). Plants were found to synthesize SA and activate SAdependent physiological processes (Klessig and Malamy, 1994). Later on it was found that SA has a role as signaling molecule and is involved in disease resistance and PCD (Delaney $\boldsymbol{e t}$ al., 1994). Exogenous SA application induces defense genes, phytoalexin production and promotes ROS generation and PCD (Shirasu et al., 1997). A large body of evidence suggest the role of SA in disease resistance and SA is known to induce systemic acquired resistance in plants (Ryals $\boldsymbol{e t}$ al., 1996). SAR is a general defense mechanism that activates in response to a pathogen that causes a necrotic lesion either as a consequence of $\mathrm{HR}$ or as a result of disease symptom development in the course of a compatible interaction (Hammerschmidt, 1999) in the distal, uninfected parts and is effective against a broad spectrum of microbial pathogens. SA activates the SAR regulatory protein, nonexpressor of PR genes (NPR1) through redox changes, which in turn drives systemic expression of PR proteins and facilitates their secretion by upregulating protein secretory pathway genes (Wang et al., 2005). Lipid metabolism also plays a central role in SAR signaling (Nandi $\boldsymbol{e t}$ al., 2004). A peptide signal system mediated by the Asp protease constitutive disease resistance 1 (CDR1) appears to be essential for SAR long-distance signaling in Arabidopsis (Xia et al., 2004). of defense response and establishment of SAR that immunizes the entire plant against further infection. Recent data suggest a complex role of SA and an involvement in the activation of HR at primary infection sites. Transgenic NahG Arabidopsis plants expressing a bacterial SA hydroxylase lose the ability to induce SAR and PR gene expression suggesting the role of SA in SAR (Delaney et al., 1994). SA accumulation itself is positively regulated. It potentiates induction of phenyl alanine ammonia-lyase (PAL) a key enzyme in SA synthesis. Arabidopsis constitutive SAR mutant hrll was used to understand the regulation of HR against pathogen in plants and it was observed that pre-existing systemic acquired resistance negatively regulates HR-associated cell-death (Devdas and Raina, 2002). Recent studies show that $\mathrm{H}_{2} \mathrm{O}_{2}$ functions upstream of SA in development of SAR and induces SA accumulation. SA promotes $P R$ gene induction in distal part of plant, enhancing defense and limiting pathogen growth. LSD1 gene, coding for novel Zinc finger protein in Arabidopsis functions as a negative regulator of plant cell death (Dietrich et al., 1994). Plant defense signal molecule SA induces rapid inhibition of ATP synthesis in tobacco cell cultures. SA has been found to affect MAP kinase (SIPK) defense.

Besides SA, NO also plays an important role in defense gene induction and HR mediated cell-death (Delle donne et al., 1998; Durner et al., 1998). NO synthase (NOS) activity was found to be enhanced upon TMV-triggered and $R$ gene-dependent HR in tobacco (Durner et al., 1998).

\section{ROLE OF MITOCHONDRIA IN HR}

Mitochondrion has found to play important role in the expression of HR associated PCD in plants. The HR/inducing bacterial virulence factor harpin disrupts mitochondrial function, and HR like cell death and disease resistance marker gene expression can also be activated in plant cells in which Bax is expressed from a viral vector. At present, it is not clear whether cytochrome c leakage also occur during HR although leakage has been observed in plant cell undergoing PCD in response to other inducer. Further evidence for the involvement of plant mitochondria in the 
regulation of HR-associated cell death comes from studies of the alternative oxidase (AOX), an IMM (inner mitochondrial membrane) enzyme that is not found in animal mitochondria. AOX catalyses electron flow directly from ubiquinol to oxygen, thereby creating an electron shunt that bypasses complex III and IV of the IMM and results in a cyanide insensitive electron-transfer pathway. AOX activation by treatment with cyanide during the HR may help to suppress cell death during the propagative phase of lesion formation and thus restrict the size of the necrotic zone (Chivasa and Carr, 1998). However, over-expression of $A O X$ has the reverse effects, providing supporting evidence for a model in which plant mitochondria have an important role as a signal generator for HR induce cell death, perhaps by generation of ROS derived from electron-transfer intermediate in the IMM (Lam et al., 1999). In plants, the mitochondrion is not the only compartment in which ROS can be generated. In addition to a plasma membrane-localized NADH oxidase, the plastid organelles can also participate in HR-associated cell death signaling. Recently, the plastid-localized protein DS9 was found to regulate the rate of HR cell death in the N gene/ TMV system (Seo et al., 2000). Overexpression of DS9 led to a delay of cell death activation by TMV. Mitochondria play an important role in ROS generation leading to LCD in mammalian cells, and recent observations suggest a similar role in plants(Maxwell et al., 2002, Amirsadeghi et al.,2006, Love et al., 2008 and Matias et al., 2010). For instance, treatment of Arabidopsis leaves with bacterial elicitors results in rapid ROS generation in mitochondria, followed by membrane pore formation, dissipation of membrane potential and decline of ATP levels (Matias $\boldsymbol{e t}$ al., 2010). The results indicate that oxidative phosphorylation is uncoupled early after the challenge, leading to decrease in oxygen consumption and ROS propagation(Matias et al., 2010 and Yao et al., 2006). Mitochondria produce ATP via respiratory oxidation of organic acids and transfer of electrons to $\mathrm{O} 2$ via the mitochondrial electron transport chain (Huang et al., 2016). This cycle produces reactive oxygen species (ROS) at various rates that can impact respiratory and cellular function, affecting a variety of signalling processes in the cell( Huang et al., 2016). Roles in redox signaling, retrograde signaling, plant hormone action, programmed cell death, and defense against pathogens have been attributed to ROS generated in plant mitochondria (mtROS) (Huang et al., 2016).

\section{ROLE OF PROGRAMMED CELL DEATH IN HR}

Programmed Cell Death (PCD) is a genetically determined process present in all multicellular organisms by which cells activate their own death (Vaux and Korsmeyer, 1999; Lam et al., 1999). It is a biological process that functions in many aspects of animal and plant development and their response to stress.

In plants,during the tracheary elements differentiation (Kuriyama and Fukuda, 2002), aerenchyma formation (Gunawardena et al., 2001), hypersensitive response (Heath, 2000) and as a consequence of several biological and chemical stresses (Beers and Mc Dowell, 2001) PCD has been observed. When a pathogen invades a plant, two types of cell death responses are mounted on the plant side. If the plant is resistant to the pathogen, a rapid cell death is frequently triggered at the primary site of infection, which constitutes the hypersensitive response (HR) and is accompanied by activation of local defense response (Heath, 2000). If the plant is susceptible, disease develops, and slower cell death develops as local and systemic infection progresses. Cell death associated with the HR may be only one of the larger set of cellular responses that are co-ordinately activated by different stress signals. Isolation of spontaneous cell death mutants in Arabidopsis and maize, in which PCD is activated in the absence of pathogens or stress, suggests that PCD in plants is under genetic control (Dietrich et al., 1994; Greenberg et al., 1994). The cell death component of the HR may function more as a signaling system than as a direct defense mechanism (Heath, 2000). Concomitant with the onset of the HR, there is transcriptional activation of defense genes encoding enzymes of phytoalexins and lignin synthesis, lytic enzymes, and 
other antimicrobial proteins as part of a massive switch in host gene expression. The expression of hsr 203J and its correlation with cell death through accumulation of proteases and protease inhibitors in tolerant and susceptible genotypes during pathogenesis of Alternaria blight in Brassica has been reported.(Mishra A et al., 2011).

\section{CONCLUSIONS}

- Breeders have often used resistance genes to introduce resistance in their crops, and with a few exceptions, all introgressed resistance genes have been shown to lack durability in the field (Pink and Puddephat, 1999). Pathogens are usually able to overcome resistance gene-mediated recognition either by shedding the corresponding elicitor gene, or by accumulating mutation in the gene, which prevents the gene product from being recognized, and thus fails to trigger the HR.

- The antimicrobial defence of multicellular organisms is thought to involve the activation of suicide pathway in infected cells termed as hypersensitive response.

- The correlation between HR related cell death during initial phase of infection and induction of MAP kinase machinery during pathogenesis will enable to provide the molecular insights for engineering resistance against several disease.

- The wide spectrum of defence responses has prompted research of defense responses to identify and use signal transduction "master switches" to engineer disease resistance. The Arabidopsis NIM 1/NPRl gene seems to be crucial in salicylic acid mediated resistance, and overexpression leads to resistance against several pathogens (Cao et al., 1998). Other enhanced disease resistance (edr) mutants have been identified. Constitutive induction of an HR has been achieved in mutants of Arabidopsis and has been shown to coincide with elevated pathogen resistance (Dietrich et al., 1994). But engineering resistance through the use of these master switches is generally not without drawbacks. Most mutants possessing constitutive expression of a defense pathway show reduced yield or plant vigour. Efforts have been made to generate transgenic plants that express the introduced gene under controlled condition only. This involves transfer of a pathogens-derived elicitor gene to the plant, expression of which is made conditional on pathogen infection by putting it under control of a tightly regulated pathogen inducible promoter. Strategies have been developed for creating novel disease resistance traits whereby transgenic plants respond to infection by a virulent pathogen with the production of an elicitor. Pathogen-induced elicitin production in transgenic tobacco generated a hypersensitive response and non specific disease resistance (Keller et al., 1999). Transgenic tobacco plants harbouring a fusion between the pathogen-inducible tobacco hsr203J gene promoter and a Phytopthora cryptogea gene encoding elicitor cryptogenin was generated. Upon infection cryptogenin was found to be induced (Keller et al., 1999). The transgenic plants showed hypersensitive response broad spectrum disease resistance. Thus exploitation of the HR by genetic means might be a strategy for creating novel disease resistance traits.

\section{REFERENCES}

1. Abdul Rashid War, Michael Gabriel Paulraj, Mohd Yousf War and Savarimuthu Ignacimuthu, (2011). Role of salicylic acid in induction of plant defense system in chickpea (Cicer arietinum L.) Plant Signaling \& Behavior November 2011; 6:11, 1787-1792

2. Alscher RG, Erturk N, Heath L .(2002). Role of superoxide dismutases (SOD) in controlling oxidative stress in plants. J Exp 
Bot 2002; 53:1331-41; PMID:11997379; DOI:10.1093/jexbot/53.372.1331.

3. Alvarez, M. E., Pennell, R. I., Meijer, P. J., Ishikawa, A., Dixon, R. A. and Lamb, C. (1998). Reactive oxygen intermediates mediate a systemic signal network in the establishment of plant immunity. Cell 92: 773-784.

4. Amirsadeghi S, Robson CA, McDonald AE, Vanlerberghe GC, (2006). Changes in plant mitochondrial electron transport alter cellular levels of reactive oxygen species and susceptibility to cell death signaling molecules. Plant Cell Physiol 2006; 47:1509-19.

5. Asada, K. (1992). Ascorbate Peroxidase a hydrogen peroxide scavenging enzyme in plants. Physiol Plant. 85: 73-96.

6. Asai, T., Tena, G., Plotnikova, J., Willmann, M. R., Chiu, W. L., Gomez-gomez, L., Boller, T., Ausubel, F. M. and Sheen, J. (2002). MAP Kinase signaling cascade in Arabidopsis innate immunity. Nature 415: 977-983.

7. Baker, B., Zambryski, P., Staskawicz, B. and Dinesh-Kumar, S. P. (1997). Signaling in plant microbe interactions. Science 276: $726-733$.

8. Baudouin, E., Charpenteau, M., Roby, D., Marco, Y., Ranjeva, R. and Ranty, B. (1997). Functional expression of a tobacco gene related to the serine-hydrolase family. Esterase activity towards short chain dinitrophenyl acylesters. Eur. J. Biochem. 248: $700-706$.

9. Beers, E. P. and Mc Dowell, J.M. (2001). Regulation and execution of programmed cell death in response to pathogen, stress and development cues. Curr. Opin. Plant. Biol. 4: 561-567.

10. Bolwell, G.P., Butt, V.S., Davies, D.R. and Zimmerlin, A. (1995). The origin of the oxidative burst in plants. Free Rad. Res. Comm. 23: $517-532$.

11. Bonas, $\boldsymbol{U}$. (1994). Hrp genes of phytopathogeneic bacteria. in: Current topics in microbiology and immunology, 192: Bacterial pathogenesis of plant and animals: Molecular and cellular mechanisms, J.L., Dangle, ed., Springer-verlag, Berlin. $79-98$.

12. Boucher, C.A., Gough, C.L. and Ariat, M. (1992). Molecular genetics of pathogenecity determinants of Pseudomonas solanacearum with special emphasis on hrp genes. Annu. Rev. Phylopath. 30: 443-461.

13. Cao, H., Li, H. and Dong, X. (1998). Generation of broad-spectrum disease resistance by over expression of an essential regulatory gene in systemic acquired resistance. Proc. Natl. Sci. USA.95: 6531-6536.

14. Century, K.S., Shapiro, A.D., Repetti, P.P., Dahlbeck, D., Holub, E. and Staskawicz, B.J. (1997). NDR1, a pathogen-induced component required for Arabidopsis disease resistance. Science. 278: 1963-1965.

15. Chen, C.H., Lin, H.J. and Feng, T.Y. (1998). An amphipathic protein from sweet pepper can dissociate harpin ${ }_{p s s}$ multimeric $^{-}$

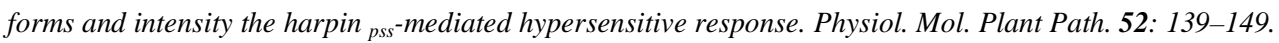

16. Chivasa, S. and Carr, J. (1998). Cyanide restores $N$-gene mediated resistance to tobacco mosaic virus in transgenic tobacco expressing salicylic acid hydroxylase. Plant Cell. 10: 1489- 1498.

17. Choudhury Shuvasish, Piyalee Panda, Lingaraj Sahoo \& Sanjib Kumar Panda, (2013). Reactive oxygen species signaling in plants under abiotic stress Plant Signaling \& Behavior,2013 8:4, e23681, DOI: 10.4161/psb.23681

18. Dangl, J.L. (1995). Piece de resistance: Novel classes of plant disease resistance genes. Cell80: 353-360.

19. Dangl, J.L., Dietrich, R.A. and Richberg, M.H. (1996). Death don't have no mercy: cell death programs in plant-microbe interactions. Plant Cell. 8: 1793-1807.

20. Delaney, T.P., Uknes, S., Vernooi, B., Friedrich, C., Weymann, K., Negrotto, D., Gaffney, T., Gutrella, M., Kessmann, H., 
Word, E. and Ryals, J. (1994). A central role of salicylic acid in plant defense resistance. Science 266: 1247-1250.

21. Delaney, T.P., Uknes, S., Vernooi, B., Friedrich, C., Weymann, K., Negrotto, D., Gaffney, T., Gutrella, M., Kessmann, H., Word, E. and Ryals, J. (1994). A central role of salicylic acid in plant defense resistance. Science 266: 1247-1250

22. Delledonne, M., Xia, Y.J., Dixon, R.A. and Lamb, C. (1998). Nitric oxide functions as a signal in plant disease resistance. Nature. 394: 585-588.

23. Devadas, S.K. and Raina, R. (2002). Pre-existing systemic acquired resistance suppresses hypersensitive response-associated cell death in Arabidopsis hrl1 mutant. Plant physiology. 128: 1234- 1244.

24. Dietrich, R.A., Delaney, T.P., Uknes, S.J., Ward, E.R., Ryals, J.A. and Dangl, J.L. (1994). Arabidopsis mutants simulating disease resistance response. Cell. 77: 565-577.

25. Dietrich, R.A., Delaney, T.P., Uknes, S.J., Ward, E.R., Ryals, J.A. and Dangl, J.L. (1994). Arabidopsis mutants simulating disease resistance response. Cell. 77: 565-577.

26. Dietrich, R.A., Richberg, M.H., Schmidt, R., Dean, C. and Dangl, J.L. (1997). A novel zinc finger protein is encoded by the Arabidopsis LSD1 gene and functions as a negative regulator of plant cell death. Cell. 88: 685-694.

27. Dixon, R.A. and Harrison, M.J. (1990). Activation, structure and organisation of genes involved in microbial defense in plants. Adv. Genet. 28: 165-234.

28. Dixon, R.A., Harrison, M.J. and Lamb, C.J. (1994). Early events in the activation of plant defense responses. Annu. Rev. Phytopathol. 32: 479-501.

29. Doke, N., Miura, Y., Sanchez, L.M., Park, H.J., Noritake, T., Yoshida, H. and Kawakita, K. (1996). The oxidative burst protects plants against pathogen attack: mechanism and role as an emergency signal for plant bio-defense. Gene. 179: 45-51.

30. Durner, J., Wendehenne, D. And Klessy, D.F. (1998). Defense gene induction in tobacco by nitric oxide, cyclic GMP, and cyclic ADP-ribose. Proc. Natl. Acad. Sci. USA. 93: 12094-12097.

31. Felton, G.W., Korth, K.L., Bi, J.L., Wesley, S.V., Huhman, D.V., Mathews, M.C., Murphy, J.B., Lamb, C., and Dixon, R.A. (1999).Inverse relationship between systemic resistance of plants to microorganisms and to infect herbivory. Curr. Biol. 9: 317-320.

32. Flor, H.H. (1971). Current status of the gene-for-gene concept. Annu. Rev. Phytopathol. 9: 275-296.

33. Foyer CH, Noctor G.(2003). Redox sensing and signalling associated with reactive oxygen in chloroplast, peroxisomes and mitochondria. Physiol Plant 2003;119:355-64

34. Galan, J.E. and collmer, A. (1999). Type III secretion machines: Bacterial devices for protein delivery into host cells. Science 284: $1322-1328$.

35. Ger, M.J., Chen, C.H., Huang, S.Y., Huang, Podile, A.R., Dayakar, B.V. and Feng, T.Y. (2002). Constitutive expression of hrap gene in transgenic tobacco plant enhances resistance against virulent bacterial pathogens by induction of hypersensitive response. Mol. Plant-Microbr Interact. 15: 764 - 773.

36. Glazebrook, J. (1999). Genes controlling expression of defense responses in Arabidopsis. Curr. Opin. Plant Biol. 2: $280-286$.

37. Goodman, R.N. and Novacky, A.J. (1994). The hypersensitive response reaction in plants to pathogens, a resistance phenomenon. APS Press, St. Paul, MN

38. Gopalan, S., Wei, W. and He, S.Y. (1996). hrp gene-dependent induction of hin 1: a plant gene activated rapidly by both harpins and the avr Pto gene-mediated signal. Plant J. 10: 591- 600. 
39. Govrin, E. and Levine, A. (2000). The hypersensitive response facilitates plant infection by the necrotrophic pathogen Botrytis cineria. Current Biology. 10: 751-757.

40. Greenberg, J.T. (1997). Programmed cell death in plant-pathogen interaction. Annu. Rev. Plant Physiol. Plant Mol. Bio. 48: $525-545$.

41. Greenberg, J.T., Guo, A., Klessig, D.F. and Ausubel, F.M. (1994). Programmed cell death in plants: A pathogen-triggered response activated co-ordinately with multiple defense functions. Cell. 77: 551-563.

42. Gunawardena, A.H., Pearce, D.M., Jackson, M.B., Hawes, C.R. and Evans, D.E. (2001). Characterization of programmed cell death during aerenchyma formation induced by ethylene or hypoxia in roots of maize. Planta. 212: 205-214.

43. Hammerschmidt, R. (1999). Induced disease resistance: how do induced plants stop pathogens? Physiol. Mol. Plant Pathol. 55: 77-84.

44. Hammond-kosak, K.E., Silverman, P., Raskin, I. and Jones, J.D.G. (1996). Race-specific elicitors of Cladosporium fulvum induce changes in cell morphology and the synthesis of ethylene and salicylic acid in tomato plants carrying the corresponding cf disease resistance gene. Plant Physiology. 110: 1381-1394.

45. Heath, M.C. (2000). Non host resistance and non specific plant defences. Curr. Opin. Plant. Biol. 3: 315-319.

46. Hirt, H. (2000). Connecting oxidative stress, auxin, and cell cycle regulation through a plant mitogen-activated protein kinase pathway. Proc. Natl. Acad. Sci. USA. 97: 2405-2407.

47. Huang, H.C., Schuurink, R., Denny, T.P., Atkinson, M.M., Baker, C.J., Yucel, I., Hutcheson, S.W. and Collmer, A. 1(988). Molecular cloning of a Pseudomonas syringae pv. Syringae gene cluster that enables Pseudomonas fluorescens to elicit the hypersensitive response in tobacco plants. J. Bact. 170: 4748- 4756.

48. Huckelhoven, R., Fodor, J., Peris, C. and Kogel, K.H. (1999). Hypersensitive cell death and papilla formation in barley attacked by the powdery mildew fungus are associated with hydrogen peroxide but not with salicylic acid accumulation. Plant Physiology. 119: 1251-1260.

49. Ichimura, K., Mizoguchi, T., Irie, K., Morris, P., Giraudat, J., Matsumoto, K. and Shinozaki, K. (1998). Isolation of ATMEKK1 (a map kinase kinase kinase) interacting protein and analysis of a MAP Kinase cascade in Arabidopsis. Biochem. Biophys. Res. Commun. 253: 532-543.

50. Ichimura, K., Mizoguchi, T., Yoshida, R., Yuasa, T. and Shinozaki, K. (2000). Various abiotic stresses rapidly activate Arabidopsis MAP Kinases ATMPK 4 and ATMPK 6.The Plant Journal. 24: 655 -665.

51. Jacques, A., Ghannam, A., Erhardt, M., de Ruffray, P., Bacillieul, F., Kaufmann, S. (2006). NECRP1, a tobacco Leucine rich repeat gene with a possible role as a modulator of the hypersensitive response. Molecular Plant-Microbe Interaction 19. 747-757

52. Jimenez A, Hernandez JA, Del Rio LA, Sevilla F, (1997). Evidence for the presence of ascorbate glutathione cycle in mitochondria and peroxisomes of pea leaves. Plant Physiol 1997; 114:275-84

53. Jones, A.D., Thomas, C.M., Hammond-Kosack, K.E., Balint-Kurti, P.J. and Jones, J.D.G. (1994). Isolation of the tomato Cf-9 gene for resistance to Cladosporium fulvum by transposon tagging. Science 266: 789 - 793.

54. Jones, J.D.G. and Dangl, J.L. (2006). The plant immune system. Nature 444: 323 - 329.

55. Keen, N.T. and Staskawicz, B.J. (1988). Host range determinants in plant pathogens and symbionts. Annu. Rev. Microbiol. 42: $421-440$. 
56. Keller, H., Pambookdjian, N., Ponchet, M., Poupet, A., Delon, R., Verrier, J.L., Roby, D. and Ricci, P. (1999). Pathogeninduced elicitin production in transgenic tobacco generates a hypersensitive response and non specific disease resistance. Plant Cell. 11: 223-235.

57. Kiedrowski, S., Kawalleck, P., Hahlbrock, K., Somssich, I. and Dangl, J.L. (1992). Rapid activation of a novel plant defense gene is strictly dependent on the Arabidopsis RPM1 disease resistance locus. EMBO J. 11: 4677-4684.

58. Klement, Z. (1971). Development of the hypersensitivity reaction induced by plant pathogenic bacteria. Proceedings of the $3^{\text {rd }}$ International Conference on Plant Pathogenic Bacteria, wageningen, 157-164.

59. Klement, Z. (1986). Hypersensitivity. In: Mount MS and Lacy GH (eds). Phytopathogenic Prokaryotes Academic Press, New York.149-177.

60. Klessig, D.F and Malamy, J.(1994). The salicylic acid signal in plants. Plant Mol Biol. 26:1439-1458

61. Klessig, D.F., Durner, J., Noad, R., Navarre, D.A., Wendehenne, D. (2000). Nitric oxide and salicylic acid signalling in plant defense. Proc. Natl. Acad. Sci. USA. 97: 8849-8855

62. Kovtun, Y., Chiu, W.L., Tena, G., Sheen, J. (2000). Functional analysis of oxidative stress-activated mitogen-activated protein kinase cascade in plants. Proceedings of the Natl. Acad. of Sci. 97: 2940-2945.

63. Kuriyama, H. and Fukuda, H. (2002). Developmental programmed cell death in plants. Curr. Opin. Plant. Biol. 5: 568-573.

64. Lam, E. (2004). Controlled cell death, plant survival and development. Mol. Cell Biol. 5: 305-315.

65. Lam, E., Ponteir, D. and del Pozo, O. (1999). Die and let live: programmed cell death in plants. Curr. Opin. Plant Biol. 2. 502-507

66. Lamb, C. and Dixon, R.A. (1997). The oxidative burst in plant disease resistance. Annu. Rev. Plant. Physiol. Plant Mol. Biol. 48: $251-275$

67. Lamb, C. and Dixon, R.A. (1997). The oxidative burst in plant disease resistance. Annu. Rev. Plant. Physiol. Plant Mol. Biol. 48: $251-275$.

68. Legendre, L., Rueter, S., Heinstein, P.F. and Low, P.S. (1993). Characterization of the oligogalacturonide induced oxidative burst in cultured soybean (Glycine max) cells. Plant Physiol. 102: 233-240.

69. Levine, A., Pennell, R.I., Alvarez, M.E., Palmer, R. and Lamb, C. (1996). Calcium-mediated apoptosis in a plant hypersensitive disease resistance response. Current Biol. 6: 427-437.

70. Levine, A., Pennell, R.I., Alvarez, M.E., Palmer, R. and Lamb, C. (1996). Calcium-mediated apoptosis in a plant hypersensitive disease resistance response. Current Biol. 6: 427-437.

71. Levine, A., Tenhaken, R., Dixon, $\boldsymbol{R}$. And Lamb, C. (1994). $\mathrm{H}_{2} \mathrm{O}_{2}$ from oxidative burst orchestrates the plant hypersensitive disease response. Cell. 79: 583-593.

72. Levine, A., Tenhaken, R., Dixon, $R$. And Lamb, C. (1994). $\mathrm{H}_{2} \mathrm{O}_{2}$ from oxidative burst orchestrates the plant hypersensitive disease response. Cell. 79: 583-593.

73. Lorrain, S., Vailleau, F., Balague, C. and Roby, D. (2003). Lesion mimic mutants: Key for deciphering cell death and defense pathways in plants? Trends Plant Sci. 8: 263-271

74. Love AJ, Milner JJ, Sadanandom A. (2008). Timing is everything: regulatory overlap in plant cell death. Trends Plant Sci 2008; 13:589-95.

75. Magnus W. Rasmussen, Milena Roux, Morten Petersen and John Mundy.(2012). MAP kinase cascades in Arabidopsis 
innate immunity. Frontiers in Plant Science July 2012, doi:10.3389/fpls.2012.00169

76. Matias D. Zurbriggen, Néstor Carrillo and Mohammad-Reza Hajirezaei, (2010). ROS signaling in the hypersensitive response When, where and what for? Plant Signaling \& Behavior April 2010;Vol. 5:4, 393-396

77. Maxwell DP, Nickels R, McIntosh L.(2002). Evidence of mitochondrial involvement in the transduction of signals required for the induction of genes associated with pathogen attack and senescence. Plant J 2002; 29:269-79.

78. Mc Dowell, J. M. and Dangl, J. L. (2000). Signal transduction in the plant immune response. Trends Biochem. Sci. 25: 79 82.

79. Mishra A, Pandey D, Puneth H, Prabhusankar R, Gupta AK, Taj G and Kumar A, (2015).Expression analysis of MAP K 4 and MAP K 6 during pathogenesis of Alternaria blight in susceptible and tolerant genotypes of Brassica juncea. Eur J Plant Pathol DOI 10.1007/s10658-015-0641-8.

80. Mishra A, Pandey D, Singh M and Kumar A.(2011).Involvement of hsr203J like gene homologue, protease and protease inhibitors in triggering differential defense response against Alternaria blight in Brassica. Australasian Plant Pathology, DOI 10.1007/s13313-011-0072-8.

81. Mittler, R., Herr, E.H., Orvar, B.L., Van Camp, W., Willekens, H., Inze, D. and Ellis, B.E. (1999). Transgenic tobacco plants with reduced capability to detoxify reactive oxygen intermediates are hyperresponsive to pathogen infection. Proc. Natl. Acad. Sci. 23: 14165-14170.

82. Mizoguchi, T., Ichimura, K. and Shinozaki, K. (1997). Environmental stress response in plants: the role of mitogen-activated protein kinases. Trends Biotechnol. 15: 15-19.

83. Mizoguchi, T., Ichimura, K., Irie, K., Morris, P., Giraudat, J., Matsumoto, K. and Shinozaki, K. (1998). Identification of a possible MAP Kinase cascade in Arabidopsis thaliana based on pair-wise yeast two hybrid analysis and functional complementation tests of yeast mutants. FEBS. Lett. 437:56-60.

84. Montesinos, E., Bonnaterra, A., Badosa, E., Frances, J., Alemany, J., Lorente, I. and Moragrega, C. (2002). Plant-microbe interactions and the new biotechnological methods of plant disease control. Int. Microbiol. 5: 169-175

85. Nandi, A., Welti, R. and Shah, J. (2004). The Arabidopsis thaliana dihydroxyacetonephosphate reductase gene SUPPRESSOR OF FATTY ACID DESATURASE DEFICIENCY 1 is required for glycerolipid metabolism and for the activation of systemic acquired resistance. Plant Cell. 16: 465-477.

86. Odjakova, M. and Hadjïvanova, C. (2001). The complexity of pathogen defense in plants. Bulg. J. Plant Physiol. 27: 101109.

87. Orozco-cardenas, M.L., Narvaez-Vasquez, J., Ryan, C.A. (2001). Hydrogen peroxide act as a second messenger for the induction of defense genes in tomato plant in response to wounding, systemin and methyl jasmonate. Plant Cell. 13: 179-191.

88. Pandey, A.K., Ger, M.J., Huang, H.E., Yip, M.K., Zeng, J. and Feng, T.Y. (2005). Expression of the hypersensitive responseassisting protein in Arabdopsis results in hairpin-dependent hypersensitive cell death in response to Erwinia carotovora. Plant Molecular Biology. 59: 771-780.

89. Parker, J.E., Holub, E.B., Frost, L.N., Falk, A., Gunn, N.D. and Daniels, M.J. (1996). Characterization of eds1, a mutation in Arabidopsis suppressing resistance to Peronospora parasitica specified by several different RPP genes. Plant Cell. 8: $2033-2046$.

90. Peterhansel, C., Freiadenhoven, A., Kurth, J., Kolsch, R. and Schulze-Lefert, P. (1997). Interaction analyses of genes required for resistance response to powdery mildew in barley reveal distinct pathways leading to leaf cell death. Plant Cell. 9: 
$1397-1409$

91. Petersen, M., Brodersen, P., Naested, H., Andreasson, E., Lindhart, U., Johansen, B., Nielsen, H.B., Lacy, M., Austin, M.J., Parker, J.E., Sharma, S.B., klessig, D.F., Martienssen, R., Mattsson, O., Jensen, A.B., Mundy, J. (2000). Arabidopsis MAPK4 negatively regulates SAR. Cell. 103: 1111 - 1120.

92. Peyne, D.M, Rossomando, A.J, Martino, P., Erickson, A.K., Her, J., Shabanowitz, J., Hunt, D.F., Weber, M.J, Sturgill, T.W. (1991). Identification of the regulatory phosphorylation sites in mitogen-activated protein kinase (MAP Kinase) EMBO Journal. 10: 885-892.

93. Pfannschmidt T, Nilsson A, Allen JF, (1999). Photosynthetic control of chloroplast gene expression. Nature 1999; 406:7314.

94. Pieterse, C.M.J and Van Loon, L.C. (1999). Salicylic acid-independent plant defense pathways.Trends Plant Sci. pathway controlling ISR in Arabidopsis. Plant Cell. 10: 1571-1580.

95. Piffanelli, P., Devoto, A. and Schulze-Lefert, P. (1999). Defense signaling pathways in cereals. Curr. Opin. Plant Biol. 2: $295-300$

96. Pillinger, M.H., Capodici, C., Rosenthal, P., Kheterpal, N., Hanft, S., Philips, M.R. and Weissmann, G. (1998). Modes of action of aspirin-like drugs: salicylates inhibit erk activation and integrin-dependent neutrophil adhesion. Proc. Natl. Acad. Sci. USA. 95:14540-14545.

97. Pink, D. and Puddephat, L. (1999). Deployment of disease resistance genes by plant transformation a "mix and match" approach. Trends Plant Sci. 4: 71-75.

98. Pitzschke, A. And Hirt, H. (2006). Mitogen-activated protein kinases and reactive oxygen species signaling in plants. Plant Physiol. 141: 351-356.

99. Pontier, D., Godiard, L., Marco, Y. and Roby, D. (1994). HSR 203J, a tobacco gene whose activation is rapid, highly localized and specific for incompatible plant pathogen interaction. Plant J. 5: 507-521.

100. Pontier, D., Tronchet, M., Rogowsky, P., Lam, E. and Roby, D. (1998). Activation of hsr203J, a plant gene expressed during incompatible plant pathogen interaction, is correlated with programmed cell death. Mol. Plant - Microbe interact. 11: 544554.

101. Ren, D., Yang, H. and Zhang, S. (2002). Cell death mediated by MAPK is associated with hydrogen peroxide production in Arabidopsis. J. Biol. Chem. 277: 559-565.

102. Reuber, T.L. and Ausubel, F.M. (1996). Isolation of Arabidopsis genes that differentiate between resistance responses mediated by RPS2 and RPM1 disease resistance genes. Plant Cell. 8: 241- 249.

103. Romeis, T., Piedras, P., Zhang, S., Klessig, D.F., Hirt, H. and Jones, J.D. (1999). Rapid Avr 9- and cf-9-dependent activation of MAP Kinases in tobacco cell cultures and leaves: convergence of resistance gene, elicitor, wound, and salicylate responses. Plant Cell. 11: 273-287

104. Rup RK. (2011). Plant responses to water stress-role of reactive oxygen species Plant Signaling \& Behavior November 2011.Vol.6:11, 1741-1745;

105. Ryals, J.A., Neuenschwander, U.H., Willits, M.G., Molina, A., Steiner, H.Y. and Hund, M.D. (1996). Systemic acquired resistance. Plant Cell 8: 1809-1819.

106. Ryals, J.A., Neuenschwander, U.H., Willits, M.G., Molina, A., Steiner, H.Y. and Hund, M.D. (1996). Systemic acquired resistance. Plant Cell 8: 1809-1819 
107. Scheel, D. (1998). Resistance response physiology and signal transduction. Curr. Opin. Plant Biol. 1: 305-310.

108. Seo, S. (2000). Reduced level of chloroplast FtsH protein in tobacco mosaic virus infected tobacco leaves accelerate the hypersensitive response. Plant Cell. 12: 917-932.

109. Shaobai Huang, Olivier Van Aken, Markus Schwarzländer, Katharina Belt, and A. Harvey Millar, (2016).The Roles of Mitochondrial Reactive Oxygen Species in Cellular Signalling and Stress Response in Plants. Plant Physiol. Vol. 171

110. Shirasu, K. and Schulze-Lefert, P. (2000). Regulators of cell death in disease resistance. Plant Molecular Biology. 44: 371385.

111. Shirasu, K., Nakajima, H., Rajasekhar, V.K., Dixon, R.A. and Lamb, C. (1997). Salicylic acid potentiates an agonistdependent gain control that amplifies pathogen signals in the activation of defense mechanisms. Plant cell. 9: 261-170.

112. Shirasu, K., Nakajima, H., Rajasekhar, V.K., Dixon, R.A. and Lamb, C. (1997). Salicylic acid potentiates an agonistdependent gain control that amplifies pathogen signals in the activation of defense mechanisms. Plant cell. 9: 261-170.

113. Suzuki, K. and Shinshi, H. (1995). Transient activation and tyrosine phosphorylation of a protein kinase in tobacco cell treated with fungal elicitor. Plant Cell. 7: 639- 647.

114. Takahashi, Y., Berberich, T., Miyazaki, A., Seo, S., Ohashi, Y. and Kusano, T. (2003). Spermine signaling in tobacco : activation of mitogen activated protein kinases by spermine is mediated through mitochondrial dysfunction. Plant J. 36: 820829.

115. Takahashi, Y., Uehara, Y., Berberich, T., Ito, A., Saitoh, H., Miyazaki, A. (2004). A subset of hypersensitive response marker genes, including hsr203j, is the downstream target of a spermine signal transduction pathway in tobacco. Plant J. 40: 586595.

116. Tampakaki, A.P., and Panopoulos, N.J. (2000). Elicitation of hypersensitive cell death by extracellularly targeted HrpZPsph produced in planta. Mol. Plant-Microbe Interact. 13: 1366- 1374.

117. Tena, G., Asai, T., Chiu, W.L. and Sheen, J. (2001). Plant mitogen-activated protein kinase signaling cascades. Curr.Opin. Plant.Biol. 4: 392-400.

118. Tronchet, M., Ranty, B., Marco, Y and Roby, D. (2001). hsr203 antisense suppression in tobacco accelerates development of hypersensitive cell death. The Plant Journal. 27: 115-127.

119. Van Gijsegem, F., Genin, S. and Boucher, C. (1993). Evolutionary conservation of pathogenecity determinants among plant and animal pathogenic bacteria. Trends Microbiol. 1: 175-180.

120. Vaux, D.L. and Korsmeyer, S.J. (1999). Cell death in development. Cell. 96: 245-254

121. Wang, D., Weaver, N.D., Kesarwani, M. and Dong, X. (2005). Induction of protein secretory pathway is required for systemic acquired resistance. Science. 308: 1036-1040.

122. Wie, Z.M., Laby, R.J., Zumoff, C.H., Bauer, D.W., He, S.Y., Collmer, A. and Beer, S.V. (1992). Harpin, elicitor of the hypersensitive response produced by the plant pathogen Erwinia amylovora. Science. 257: 85-88.

123. Xia, Y., Suzuki, H., Borevitz, J., Blount, J., Guo, Z., Patel, K., Dixon. R.A., and Lamb, C. (2004). An extracellular aspartic protease functions in Arabidopsis disease resistance signalling. EMBO J. 23: 980-988.

124. Xie, Z. and chen, Z. (2000). Harpin-induced hypersensitive cell death is associated with altered mitochondrial functions in tobacco cells. Mol. Plant-Microbe Interaction. 13: 183-190.

125. Yang, K.Y., Liu, Y.D. and Zhang, S.Q. (2001). Activation of a mitogen-activated protein kinase pathway is involved in disease 
resistance in tobacco. Proc. Natl. Acad. Sci. USA. 98: 741-746.

126. Yano, A., Suzuki, K. and Shinshi, H. (1999). A signalling pathway, independent of the oxidative burst that leads to hypersensitive cell death in cultured tobacco cells includes a serine protease. Plant Journal. 18: 105-109.

127. Yao N, Greenberg JT, (2006). Arabidopsis ACCELERATED CELL DEATH2 modulates programmed cell death. Plant Cell 2006; 18:397-411.

128. Zhang, S. and Klessig, D.F. (1997). Salicylic acid activates a 48-KD MAP Kinase in tobacco. Plant Cell. 9: 809-824.

129. Zhang, S. and Klessig, D.F. (1998). Resistance gene N-mediated de novo synthesis and activation of a tobacco mitogenactivated protein kinase by tobacco mosaic virus infection. Proc. Natl. Acad. Sci. USA. 95: 7433-7438.

130. Zhang, S., Du, H. and Klessig, D.F. (1998). Activation of the tobacco SIP Kinase by both a cell wall-carbohydrate elicitor and purified proteinaceous elicitins from Phytopthora spp. Plant Cell. 10: 435 -450.

131. Zhang, S. Q. and Klessig, D.F. (2001). MAPK cascades in plant defense signaling.Trends Plant Sci. 6: 520-527. 
